\title{
Elevated HOXA1 expression correlates with accelerated tumor cell proliferation and poor prognosis in gastric cancer partly via cyclin D1
}

Chenwei Yuan ${ }^{1 \dagger}$, Xingwu Zhu ${ }^{1+}$, Yang Han ${ }^{1}$, Chenlong Song ${ }^{1}$, Chenchen Liu', Su Lu², Meng Zhang ${ }^{2}$, Fudong Yu', Zhihai Peng ${ }^{1}$ and Chongzhi Zhou ${ }^{1,3^{*}}$

\begin{abstract}
Background: HOXA1 is a member of the Homeobox gene family, which encodes a group of highly conserved transcription factors that are important in embryonic development. However, it has been reported that HOXA1 exhibits oncogenic properties in many malignancies. This study focused on the expression and clinical significance of HOXA1 in gastric cancer (GC).

Methods: To assess the mRNA and protein expression of HOXA1 and cyclin D1 in GC tissues, we utilized qRT-PCR and western blotting, respectively. The effects of HOXA1 on GC cell proliferation, migration, and invasion, as well as xenograft tumor formation and the cell cycle were investigated in our established stable HOXA1 knockdown GC cell lines. The protein expression of HOXA1 and cyclin D1 was examined by immunohistochemistry using GC tissue microarrays (TMA) to analyze their relationship on a histological level. The Kaplan-Meier method and cox proportional hazards model were used to analyze the relationship of HOXA1 and cyclin D1 expression with GC clinical outcomes.

Results: HOXA1 mRNA and protein expression were upregulated in GC tissues. Knockdown of HOXA1 in GC cells not only inhibited cell proliferation, migration, and invasion in vitro but also suppressed xenograft tumor formation in vivo. Moreover, HOXA1 knockdown induced changes in the cell cycle, and HOXA1 knockdown cells were arrested at the G1 phase, the number of cells in S phase was reduced, and the expression of cyclin D1 was decreased. In GC tissues, high cyclin D1 mRNA and protein expression were detected, and a significant correlation was found between the expression of HOXA1 and cyclin D1. Survival analysis indicated that HOXA1 and cyclin D1 expression were significantly associated with disease-free survival (DFS) and overall survival (OS). Interestingly, patients with tumors that were positive for HOXA1 and cyclin D1 expression showed worse prognosis. Multivariate analysis confirmed that the combination of HOXA1 and cyclin D1 was an independent prognostic indicator for OS and DFS.
\end{abstract}

Conclusion: Our data show that HOXA1 plays a crucial role in GC development and clinical prognosis. HOXA1, alone or combination with cyclin D1, may serve as a novel prognostic biomarker for GC.

Keywords: HOXA1, cyclin D1, Gastric cancer, Biomarker, Prognosis

\footnotetext{
*Correspondence: chongzhi_zhou@163.com

${ }^{\dagger}$ Equal contributors

'Department of General Surgery, Shanghai General Hospital, Shanghai

Jiaotong University School of Medicine, Shanghai 200080, P. R. China

${ }^{3}$ Department of General Surgery, Kashgar Prefecture Second People's

Hospital, Kashgar, Xinjiang Uyghur Autonomous Region 844000, P. R. China

Full list of author information is available at the end of the article
} 


\section{Background}

Gastric cancer (GC) is a leading cause of cancer-related death worldwide $[1,2]$, and it is also the third most common cancer and a major cause of cancer-related death in China [3]. Although much progress has been made in the diagnosis and treatment of $\mathrm{GC}$ in recent years, the survival rate remains unsatisfactory (20-25\%) [4], which may be attributable in part to late diagnosis and the postoperative recurrence or metastasis of primary GC. There are no distinct symptoms of GC, and the current tumor markers are of little use for prognostic evaluation $[5,6]$. Thus, the identification of new useful biomarkers for early detection and prognosis in patients with GC is of great importance.

HOX genes, which were first discovered in Drosophila melanogaster mutants in the early 1900s, constitute a highly conserved subgroup of the homeobox superfamily that encodes transcription factors with a 60-amino acid domain called the homeodomain. HOX genes play important roles in embryonic development by regulating numerous processes, including cell proliferation, apoptosis, differentiation, angiogenesis, and so on [7-9]. In mammals, there are 39 HOX genes, which are located in 4 chromosomal clusters, referred to as $\operatorname{HOX} A, B, C$, and $D$, that each contain 9-11 genes [9]. During normal vertebrate development, HOX genes play an important role in the mechanisms underlying the following three basic precepts: spatial collinearity, posterior prevalence, and temporal collinearity [8]. However, aberrant expression of HOX genes occurs in many cancers, such as acute leukemia, lung cancer, and cervical carcinoma, among others [10-14].

In our previous studies, we detected several differentially expressed HOX genes in GC using high-throughput cDNA microarrays [15]. Among these genes, HOXA1 was more highly expressed in 8 out of 12 tumor tissues than in normal tissues[15]. HOXA1 is a part of the A cluster on chromosome 7, and it encodes a DNA binding transcription factor that regulates the expression of genes involved in morphogenesis, cell proliferation, and differentiation [16-18]. Some studies have demonstrated the roles that HOXA1 plays in tumorigenesis. Brock et al. [19] showed that HOXA1 is a critical mediator of mammary tumor progression in humans. A recent study showed that loss of HOXA1 impairs cellular progression by blocking the G1-S transition in HeLa cells [20]. In addition, Zhang et al. [21] demonstrated that ectopic expression of HOXA1 in MCF7 breast cancer cells upregulates cyclin D1. Interestingly, cyclin D1 has been found to be highly expressed in GC [22, 23] and many other malignancies such as breast cancer [24] and cutaneous melanoma [25]. Cyclin D1 is well known for its role in the response to the mitogenic signals that promote progression through the G1-S checkpoint of the cell cycle [26]. Recently Seo et al.
[27] reported that downregulation of cyclin D1 in GC cells by a lentivirus significantly inhibited cell function and motility in vitro, and significantly inhibited cancer growth when engrafted into nude mice. However, the relationship between HOXA1 and cyclin D1 in GC has not been elucidated in detail.

The current study aimed to investigate the expression and clinical significance of HOXA1 in GC. First, we assessed the expression of HOXA1 in GC at both the transcriptional and translational levels. Second, we studied the effects of HOXA1 on GC cell proliferation, migration, invasion, cell cycle progression, and xenograft tumor formation by knocking down the expression of HOXA1, and we found that the expression of cyclin D1 was also decreased. Third, we determined the mRNA and protein expression of cyclin D1 in GC to examine the relationship between HOXA1 and cyclin D1. Finally, we investigated the relationship of HOXA1 and cyclin D1 with clinical characteristics and the prognostic value of HOXA1, either alone or in combination with cyclin D1, using GC tissue microarrays (TMA). We found that HOXA1 plays a role in the development and clinical prognosis of $\mathrm{GC}$, and it may be useful as a novel prognostic biomarker for GC, either alone or in combination with cyclin D1.

\section{Methods}

\section{Patients and specimens}

Fresh primary cancer and paired adjacent normal tissue specimens were collected from $48 \mathrm{GC}$ patients (33 males and 15 females) in the Department of General Surgery of Shanghai General Hospital. The tissues were collected after surgical resection, frozen immediately in liquid nitrogen, and stored at $-80{ }^{\circ} \mathrm{C}$ until RNA and protein extraction. A total of 264 preserved human GC tissue specimens (from 157 males and 107 females) from Shanghai General Hospital were paraffin embedded for TMA construction. Disease-free survival (DFS) and overall survival (OS) were defined as the interval from surgery to clinically or radiologically proven recurrence/ metastasis and death, respectively. Tumor staging was based on pathological outcomes according to the guidelines of the International Union against Cancer (UICC) [28], and the diagnoses were confirmed by two pathologists. Patients who had never received chemotherapy or radiotherapy were enrolled in this study. All of the patients provided written informed consent. The study was approved by the Ethics Committee of Shanghai General Hospital.

\section{Cell lines and the establishment of HOXA1 knockdown cell lines}

The human gastric cancer cell lines HGC-27, SGC-7901, MGC-803, BGC-823, and AGS were purchased from the Type Culture Collection of the Chinese Academy of 
Science (Shanghai, China). Cells were cultured in 1640/ F12k medium supplemented with $10 \%$ fetal bovine serum (FBS; Gibco, Australia) and $1 \%$ penicillin-streptomycin at $37{ }^{\circ} \mathrm{C}$ in a humidified atmosphere containing $5 \% \mathrm{CO}_{2}$.

The HOXA1 RNAi lentiviral expression plasmid was purchased from Scigebio Biotechnology Co., Ltd. (Shanghai, China). The oligonucleotides used to generate the shRNA targeting HOXA1 (shHOXA1) were forward: AGTTATCT TAGCTGGATATAA and reverse: TTATATCCAGCTAA GATAACT. SGC-7901 and BGC-823 cells were transfected with $1 \times 10^{8}$ transducing units $/ \mathrm{mL}$ of lentivirus particles. The cells were subjected to antibiotic selection (with $1.2 \mu \mathrm{g} / \mathrm{mL}$ puromycin) after transfection. As a result, two stable cell lines (SGC-7901-shHOXA1 and BGC-823-shHOXA1) were established. Cells transfected with a control shRNA sequence were used as controls (SGC-7901-Control and BGC-823-Control).

\section{RNA extraction and quantitative real-time PCR (qRT-PCR)} Total RNA from GC cells and tissue specimens was extracted with TRIzol reagent (Invitrogen, NY, USA) according to the manufacturer's instructions, and $2 \mu \mathrm{g}$ of total RNA from each sample were reverse transcribed into cDNA using PrimeScript ${ }^{\mathrm{Tm}}$ RT Master Mix (Perfect Real Time; Takara, Shiga, Japan) according to the manufacturer's instructions. qRT-PCR was performed using SYBR $^{\oplus}$ Premix Ex Taq $^{\text {тм }}$ (Tli RNaseH Plus; Takara) in a ViiA $^{\text {тм }} 7$ Real-time PCR System (Applied Biosystems, NY, USA) according to the manufacturer's protocol. The amplification was performed as follows: an initial denaturation step for $2 \mathrm{~min}$ at $95{ }^{\circ} \mathrm{C}$ followed by 40 cycles of denaturation for $10 \mathrm{~s}$ at $95{ }^{\circ} \mathrm{C}$, annealing for $30 \mathrm{~s}$ at $59{ }^{\circ} \mathrm{C}$, and elongation for $30 \mathrm{~s}$ at $72{ }^{\circ} \mathrm{C}$, and a final extension step at $72{ }^{\circ} \mathrm{C}$ for $30 \mathrm{~s}$. The specific primers used were as follows: HOXA1 sense, 5'-CGGCTTCCTGTGCTAAGTCT-3' and antisense, 5'-TTCATTGTGCCATCCATCAC-3'; cyclin D1 sense, 5'-GTGTATCGAGAGGCCAAAGG-3' and antisense, 5'-GCAACCAGAAATGCACAGAC-3'; and $\beta$-actin sense, 5'-CATGTACGTTGCTATCCAGGC-3' and antisense, 5'-CTCCTTAATGTCACGCACGAT-3'. $\beta$-Actin was used as an internal control, and the relative quantities ( $\Delta$ cycle threshold [Ct] values) of each transcript were normalized to $\beta$-actin. Each reaction was repeated in triplicate. The fold changes $\left(2^{-\Delta \Delta \mathrm{Ct}}\right)$ in $H O X A 1$ and cyclin D1 mRNA expression were calculated using the following formulae: HOXA1 $\Delta \mathrm{Ct}=($ Avg. HOXA1_Ct Avg. $\beta$-actin_Ct), HOXA1 $\Delta \Delta \mathrm{Ct}=(\mathrm{HOXA} 1 \Delta \mathrm{Ct}$ tumor HOXA1 $\Delta \mathrm{Ct}$ _non-tumor); cyclin $\mathrm{D} 1 \Delta \mathrm{Ct}=($ Avg. cyclin D1_Ct - Avg. $\beta$-actin_Ct $), \quad$ cyclin $\mathrm{D} 1 \Delta \Delta \mathrm{Ct}=($ cyclin D1 $\Delta$ Ct_tumor - cyclin D1 $\Delta \mathrm{Ct}$ _non-tumor).

\section{Protein extraction and western blotting}

Total protein was isolated from GC cells and tissue specimens using RIPA Lysis Buffer (Beyotime Biotechnology,
Jiangsu, China). Protein concentration was measured using the BCA protein assay kit (Beyotime Biotechnology). Samples containing $40 \mu \mathrm{g}$ of protein were separated by $10 \%$ sodium dodecyl sulfate-polyacrylamide gel electrophoresis (SDS-PAGE), and the separated proteins were then transferred onto PVDF membranes. The membranes were blocked in $5 \%$ fat-free milk solution containing $0.1 \%$ Tween-20 for $1 \mathrm{~h}$ at room temperature. Membranes were then incubated with an anti-HOXA1 antibody (1:1,000; Abcam, Cambridge, UK), an anti-cyclin D1 antibody (1:100; Abcam), and an anti- $\alpha / \beta$-tubulin antibody (1:1,000; Cell Signaling Technology, MA, USA) at $4{ }^{\circ} \mathrm{C}$ overnight. Next, the membranes were incubated with a secondary antibody (1:10,000; Jackson ImmunoReasearch Inc., PA, USA) conjugated to horseradish peroxidase for $1 \mathrm{~h}$ at room temperature. After washing with TBST buffer, the bands were visualized with Immobilon ${ }^{\text {тм }}$ Western Chemiluminescent HRP Substrate (Millipore, MA, USA) according to the manufacturer's instructions.

\section{Cell counting Kit-8 (CCK-8) assay}

To observe the effect of HOXA1 knockdown on cell proliferation in vitro, the CCK- 8 assay (Dojindo, Kumamoto, Japan) was employed to generate cell growth curves. Briefly, cells were plated in triplicate in 96-well cell culture plates at a density of 2,000 cells/well. At various time points $(24,48,72,96$, and $120 \mathrm{~h})$, the cells were incubated with $10 \mu \mathrm{L}$ of CCK-8 solution for $2 \mathrm{~h}$ at $37{ }^{\circ} \mathrm{C}$, and then the absorbance at $450 \mathrm{~nm}$ was measured on a Gen5 microplate reader (BioTek, VT, USA). The experiment was performed independently in triplicate.

\section{Plate colony formation assay}

To evaluate colony formation, 800 log-phase cells were seeded in 6-well plates. After a 14-day incubation, the cells were fixed in methyl alcohol for $15 \mathrm{~min}$ and dyed with crystal violet for $15 \mathrm{~min}$. Colonies were then counted, and the plates were photographed. The experiment was performed independently in triplicate.

\section{Migration and invasion assays}

For these assays, $1 \times 10^{5}$ cells in serum-free medium were seeded in the upper compartment of a transwell chamber (Millipore). The transwell membrane was either coated with Matrigel (for invasion; BD, CA, USA) or without (for migration). Then, the lower chamber was filled with $600 \mu \mathrm{L}$ of basal medium containing $10 \%$ FBS. After incubation at $37{ }^{\circ} \mathrm{C}$ in a humidified incubator containing $5 \% \mathrm{CO}_{2}$ for $24 \mathrm{~h}$, the migrated or invaded cells on the lower membrane were fixed with methanol, stained with crystal violet, and then counted. The experiment was performed independently in triplicate. 


\section{Nude mice xenograft models}

Four-week-old male BALB/C nude mice were used to establish GC xenografts. The mice were then randomly divided into 2 groups $(n=5)$, and $5 \times 10^{6}$ BGC-823shHOXA1 or BGC-823-Control cells suspended in $100 \mu \mathrm{L}$ of PBS were subcutaneously injected into their flanks. All mice were sacrificed 21 days after injection. Then, tumor mass and size were measured. Tumor volume was calculated using the following formula: volume $=$ width $^{2} \times$ length $\times 0.5$ [29]. Paraffin sections of the xenograft tissues were prepared for hematoxylin and eosin (H\&E) staining and IHC with an anti-Ki67 antibody (1:500; Abcam). All animal studies were performed in accordance with the Shanghai General Hospital Animal Care guidelines. All efforts were made to minimize animal suffering.

\section{Flow cytometry analysis of the cell cycle}

The Cell Cycle Kit (BD) was utilized to analyze the cell cycle. Cells were harvested, washed in phosphate buffered saline (PBS) for $5 \mathrm{~min}$, and collected by centrifugation at $1,000 \mathrm{rpm}$ for $10 \mathrm{~min}$. Then, $5 \mathrm{~mL}$ of prechilled $70 \%$ ethanol was used to fix the cells overnight at $4{ }^{\circ} \mathrm{C}$. The cells were then washed, centrifuged, and resuspended in $0.5 \mathrm{~mL}$ of PI/RNase Staining Buffer. After incubation for $15 \mathrm{~min}$, the cells were analyzed by flow cytometry (BD Accuri). The experiment was performed independently in triplicate.

\section{5-Ethynyl-2'- deoxyuridine (EdU) incorporation assay}

The EdU incorporation assay was performed using the Cell-Light ${ }^{\mathrm{Tm}}$ EdU Apollo $^{\circledR} 643$ In Vitro Imaging Kit (RiboBio, Guangzhou, China) according to the manufacturer's instructions. Cells were seeded on confocal dishes; when they reached about $50 \%$ confluency, EdU labeling medium was added, and the cells were incubated for about $2 \mathrm{~h}$. The cells were then fixed with $4 \%$ formaldehyde for $30 \mathrm{~min}$ and treated with $0.5 \%$ Triton X-100 for $30 \mathrm{~min}$ at room temperature. After washing three times with PBS, the cells were dyed with Apollo for $30 \mathrm{~min}$. Then, Hoechst $33342(5 \mu \mathrm{g} / \mathrm{mL})$ was used to dye the DNA in the cells, and the cells were visualized with a confocal microscope. The experiment was performed independently in triplicate.

\section{Tissue microarray (TMA) construction and immunohistochemistry (IHC)}

The method used to construct the TMA was previously reported [15]. After dewaxing and rehydration, the paraffin-embedded sections were drowned in boiled citrate buffer (0.01 M, pH 6.0) for antigen retrieval. Next, an anti-HOXA1 antibody (1:100; Abcam) and anti-cyclin D1 antibody (1:50; Abcam) were incubated with the slides at $4{ }^{\circ} \mathrm{C}$ overnight. Then, the anti-mouse or anti-rabbit EnVision ${ }^{\mathrm{Tm}}$ two-step Visualization System (Gene Tech, Shanghai, China) was used to detect the primary antibody for $30 \mathrm{~min}$ at room temperature. Finally, the slides were counterstained with Mayer's hematoxylin and covered with coverslips.

\section{Evaluation of immunostaining}

We semi-quantitatively scored the expression levels of HOXA1 and cyclin D1 by calculating the staining intensity and area, according to the method of Han et al. [15], with slight modifications. The staining intensity was scored as 0 (negative), 1 (weak), 2 (moderate), or 3 (strong). The staining area was scored as 0 (0 \%), 1 (1-25\%), 2 (26-50\%), or $3(51-100 \%)$ based on the percentage of positively stained cells. The final immunostaining score (IS) for each case was calculated by adding the staining intensity score to the staining area score. According to the IS, our specimens were divided into 2 groups as follows: positive HOXA1 and cyclin D1 expression was defined as an IS $\geq 3(3,4,5$, and 6$)$, and negative expression was defined as an IS $<3$ ( 0 and 2$)$.

\section{Statistical analysis}

All statistical analyses were carried out using SPSS version 19.0 (SPSS, Inc., Chicago, IL, USA). The 2-tailed Student's t-test was used to calculate the difference in the mRNA expression of HOXA1 and cyclin D1 between cancer tissues and paired normal mucosae. The correlation between HOXA1 and cyclin D1 mRNA and protein expression was calculated using Spearman's correlation coefficient test. The significance of the differences among covariates was determined using two-tailed $\chi^{2}$ or Fisher's exact tests where appropriate. The Kaplan-Meier method was used to calculate the survival rates, and the log-rank test was used to compare survival curves. Cox proportional hazards models were utilized to investigate the independent risk factors for death, and significant factors were selected for the final multivariate regression model. The in vitro and in vivo data were expressed as mean \pm SD and were compared using the 2-tailed Student's t-test. Differences with $\mathrm{P}$ values less than 0.05 were considered statistically significant.

\section{Results}

HOXA1 is upregulated in GC tissues compared to the levels in corresponding adjacent normal mucosae

The mRNA expression of HOXA1 was examined in 48 GC tissue and paired mucosa samples by qRT-PCR. A majority of the GC samples $(32,66.7 \%)$ showed a $\geq 2$ fold increase in HOXA1 mRNA levels compared with the levels in adjacent normal mucosae (Fig. 1a). The relative expression $(\triangle \mathrm{Ct})$ of $H O X A 1 \mathrm{mRNA}$ in cancerous tissue was significantly lower than that in normal mucosa (9.57 \pm 1.84 vs. $11.23 \pm 1.66$, respectively; $P<0.001)$. 


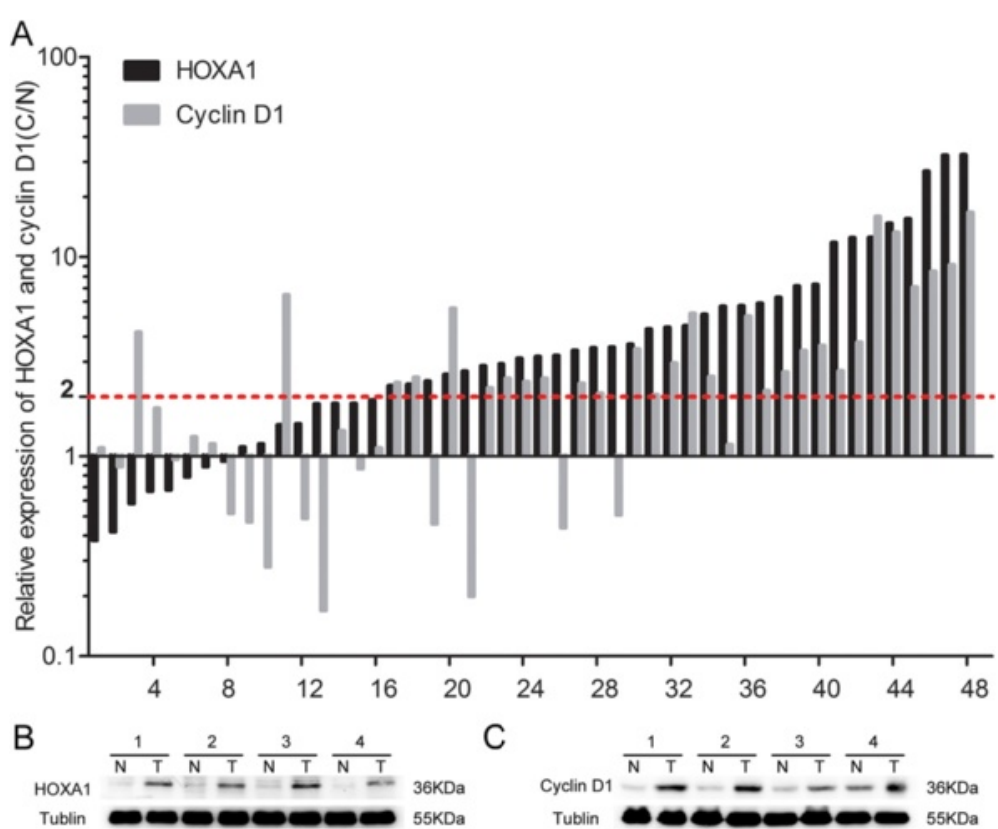

Fig. 1 Expression of HOXA1 and cyclin D1 in human gastric cancer (GC) tissues. a Relative HOXA1 and cyclin D1 mRNA expression in 48 tumor tissues and paired adjacent normal mucosae as determined by qRT-PCR. An increase (at least 2-fold) in HOXA1 and cyclin D1 mRNA levels compared to noncancerous tissue was observed in $32(66.7 \%)$ and $29(60.4 \%)$ of the GC tissue samples. The $2-\Delta \Delta C$ t method was used to calculate the fold change. $\mathbf{b}$ Western blotting showed higher HOXA1 protein expression in GC tissues than in the matched adjacent normal mucosae. c Western blotting showed that cyclin D1 protein expression was upregulated in GC tissues compared to the levels in the matched adjacent normal mucosae

Similarly, western blotting revealed a significant elevation of HOXA1 protein expression in GC tissues compared with the expression in adjacent normal mucosae (Fig. 1b), suggesting that HOXA1 expression was elevated at both the transcriptional and translational levels.

\section{Knockdown of HOXA1 expression inhibits GC cell proliferation}

To explore the function of HOXA1 in GC, we suppressed the expression of HOXA1. Western blotting demonstrated that HOXA1 expression was higher in SGC-7901 and BGC-823 cells than in the other tested cell lines (Fig. 2a, b). The efficiency of shRNAmediated knockdown in SGC-7901 and BGC-823 cells was confirmed by western blotting and qRT-PCR (Fig. 2c, d). Next, we performed CCK- 8 and plate colony formation assays to assess the role of HOXA1 in GC cell growth. As shown in Fig. 2e, significant inhibition of cell growth was observed in the sh-HOXA1 group compared with the growth in the control groups. In addition, the colony formation assay showed that HOXA1 knockdown reduced colony formation compared with that in the control group $(P<0.001$; Fig. $2 \mathrm{f}, \mathrm{g})$. These results indicated that knockdown of HOXA1 expression inhibited GC cell proliferation.

\section{Knockdown of HOXA1 expression inhibits GC cell migration and invasion}

Cell migration and invasion are necessary for tumor development and metastasis. We used transwell chambers either uncoated or precoated with Matrigel to assess the effects of HOXA1 expression on cell migration and invasion, respectively. Knockdown of HOXA1 inhibited the migration and invasion of GC cells compared with that of the control cells $(P<0.001$; Fig. 3$)$, indicating that HOXA1 increases the migrant and invasive behavior of these cells. These findings indicated that upregulation of HOXA1 may contribute to GC progression by promoting cell migration and invasion.

\section{Knockdown of HOXA1 expression inhibits xenograft tumor growth}

To determine the role of HOXA1 in tumorigenesis, BGC-823-shHOXA1 cells and BGC-823-Control cells were subcutaneously injected into nude mice, and the resulting tumors were isolated 3 weeks later. As shown in Fig. 4, the growth index of the tumors in the BGC823-shHOXA1 group was significantly lower than that of tumors in the BGC-823-Control group. Moreover, HOXA1 knockdown significantly inhibited overall tumor growth as assessed by the measurements of tumor volume and mass $(P<0.05$ and $P<0.01$, respectively; Fig. 4b, c). Particularly, the average tumor volume and 


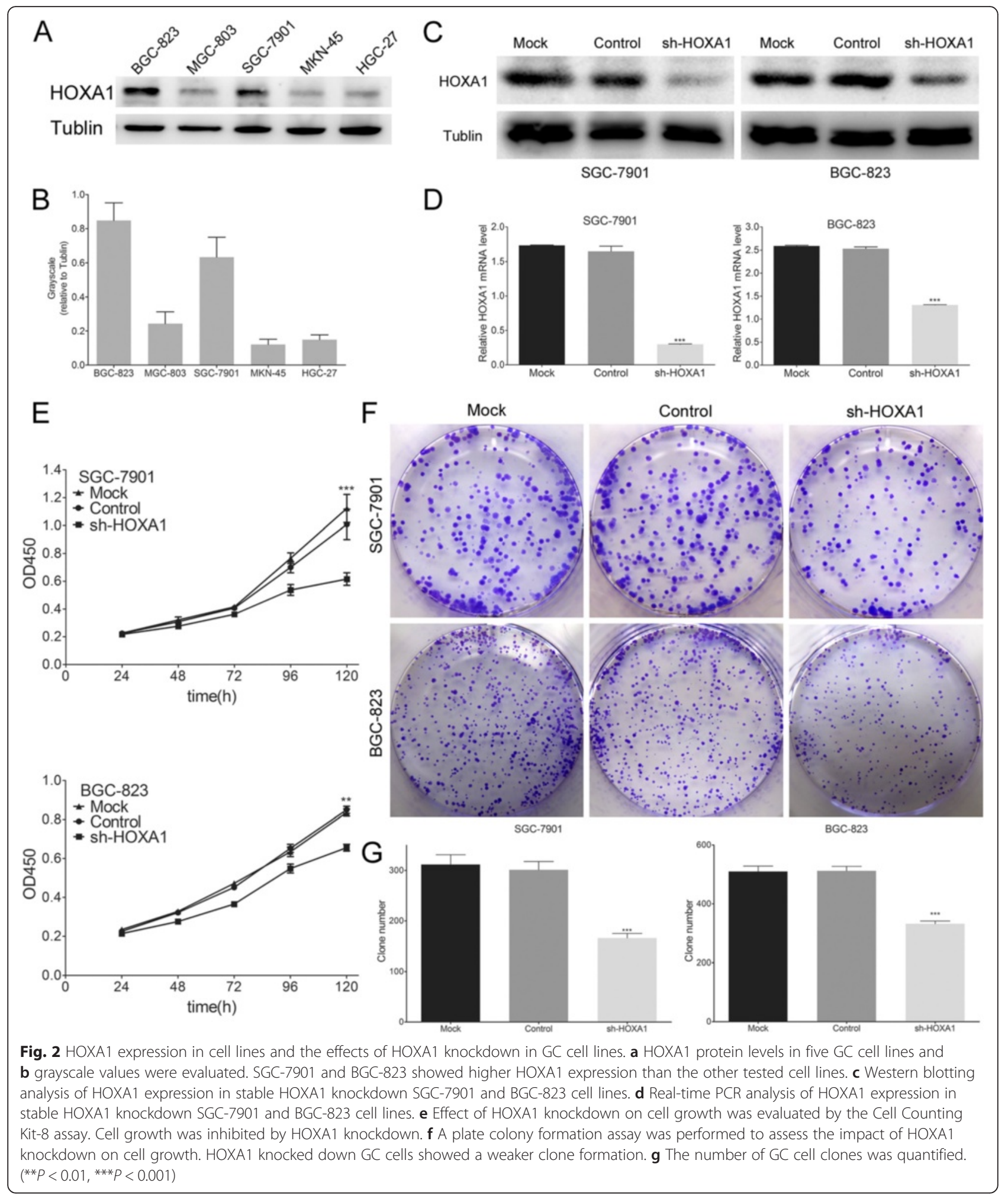

weight of the BGC-823-shHOXA1 group were dramatically lower than those of the BGC-823-Control group; tumor volume at 3 weeks was $34.29 \pm 21.80 \mathrm{~mm}^{3}$ vs. $288.70 \pm 183.82 \mathrm{~mm}^{3}$, respectively, and tumor weight was $23.80 \pm 15.66 \mathrm{mg}$ vs. $176.40 \pm 88.25 \mathrm{mg}$, respectively. In addition, IHC was utilized to detect Ki67, a cellular proliferation marker, in the xenografts. The expression of Ki67 was significantly weaker in the xenografts 


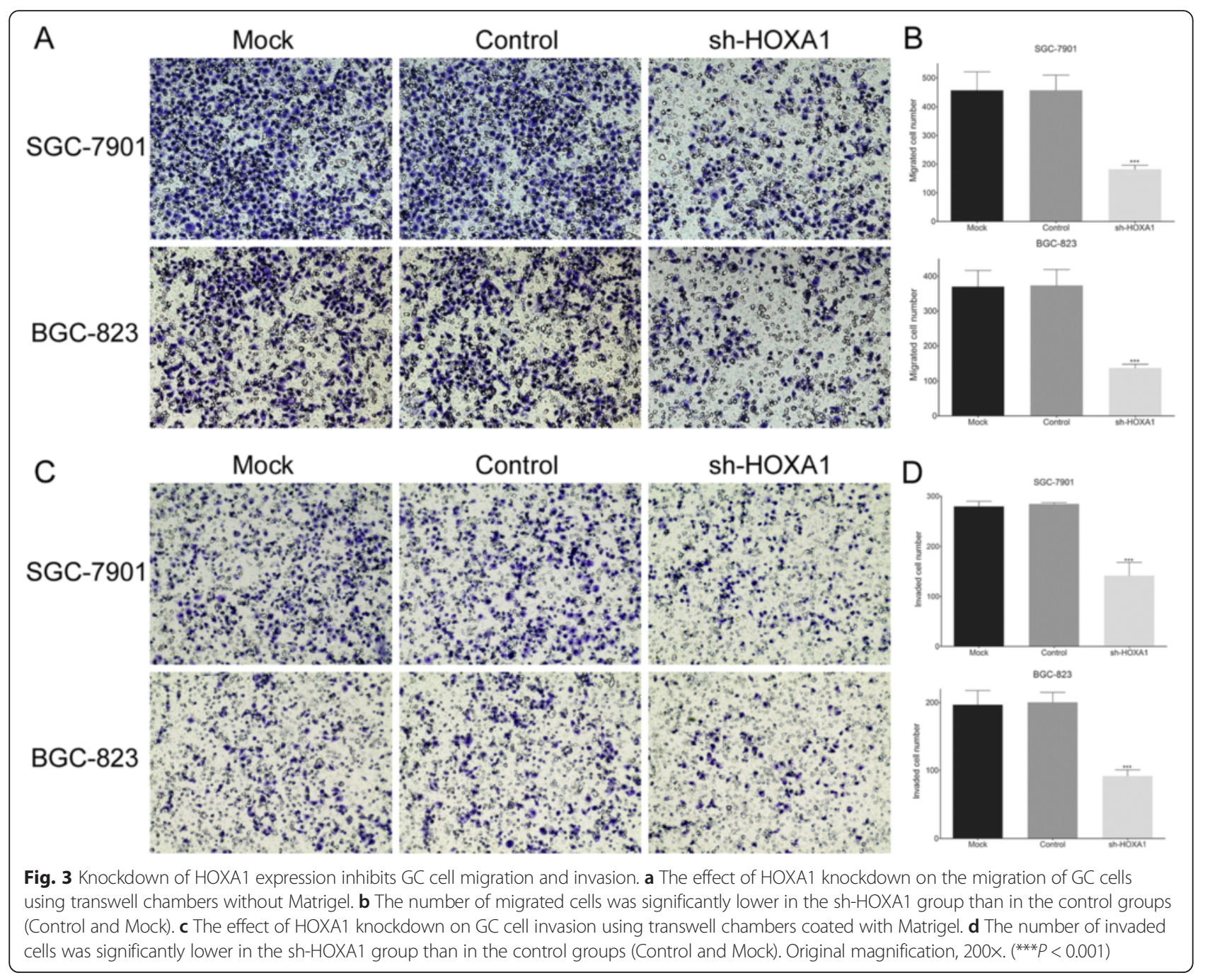

containing BGC-823-shHOXA1 cells than in xenografts containing BGC-823-Control cells (Fig. 4d). These findings showed that downregulation of HOXA1 expression suppressed GC tumor growth in vivo.

Knockdown of HOXA1 expression induces changes in the cell cycle of GC cells and decreases cyclin D1 expression Next, we utilized flow cytometry analysis to determine the role of HOXA1 in the cell cycle and found that HOXA1 knockdown cells were arrested in the G1 phase and the number of $S$ phase cells was reduced (Fig. 5a, b). Then, we used an EdU incorporation assay to determine how HOXA1 knockdown affects the number of proliferating cells. The results showed that the number of EdU-positive cells in the shHOXA1 group was lower than that in the control group (Fig. 5c, d). As EdU is incorporated into DNA during synthesis in $\mathrm{S}$ phase, fewer EdU-positive cells means a reduction of the number of cells in $\mathrm{S}$ phase, which is in accord with the cell cycle analysis results. Cyclin D1 has been reported to play an important role in cell cycle progression, mainly via regulation of the G1-S-phase transition [30]. Then, we assessed cyclin D1 expression in our established stable GC cells and found that expression was markedly lower in SGC-7901-shHOXA1 and BGC-823-shHOXA1 cells than in the control cells (Fig. 5e). These results indicated that HOXA1 knockdown induced an accumulation of SGC-7901 and BGC-823 cells in the G1 phase and a reduction in the number of cells in $S$ phase and the expression of cyclin D1.

Cyclin D1 is upregulated in GC tissues compared with the levels in the corresponding adjacent normal mucosae We then determined the mRNA expression of cyclin D1 in GC tissues and paired mucosae. Twenty-nine (60.4 \%) of the GC samples showed a $\geq 2$-fold increase in cyclin D1 mRNA levels compared with the levels 


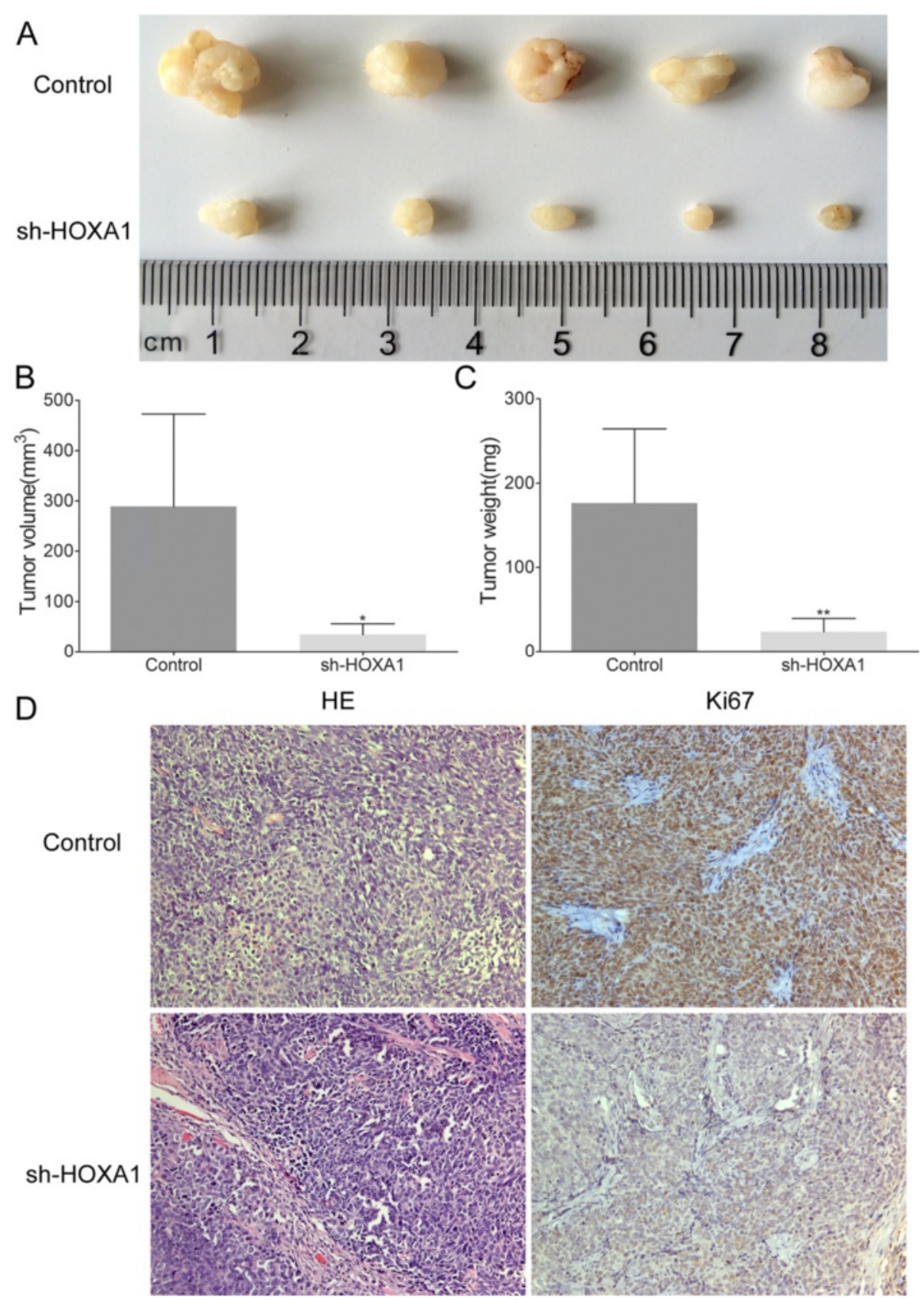

Fig. 4 Knockdown of HOXA1 expression suppresses tumorigenicity in vivo. a BGC-823-shHOXA1 and BGC-823-Control cells were injected subcutaneously into nude mice. After 3 weeks, the tumors were dissected. The tumors of mice in the BGC-823-shHOXA1 group were smaller than the tumors of BGC823-Control group. b Tumor volume of the BGC-823-Control and BGC-823-shHOXA1 groups 3 weeks after cell injection (* $P<0.05)$. c Tumor weight of the BGC-823-Control and BGC-823-shHOXA1 groups 3 weeks after cell injection (**P<0.01). d H\&E- and IHC-stained paraffin-embedded sections obtained from the xenografts. IHC staining showed that the expression of Ki67 was weaker in the BGC-823-shHOXA1 group than in the BGC-823-Control group. Original magnification, 200x

in the adjacent normal mucosae (Fig. 1a). The relative expression $(\Delta \mathrm{Ct})$ of cyclin D1 mRNA in GC was significantly lower than that in normal mucosae $(4.74 \pm 1.34$ vs. $5.77 \pm 1.35$, respectively; $P<0.001)$. Interestingly, increased HOXA1 and cyclin D1 mRNA levels were detected in 27 (56.3 \%) GC tissues, and a statistically significant correlation was found $(\mathrm{r}=0.651, P<0.001)$. Similarly, western blotting revealed a significant elevation of cyclin D1 protein expression in GC tissues compared with the levels in the adjacent normal mucosae (Fig. 1c), suggesting that cyclin D1 expression is elevated at both the transcriptional and translational levels. 


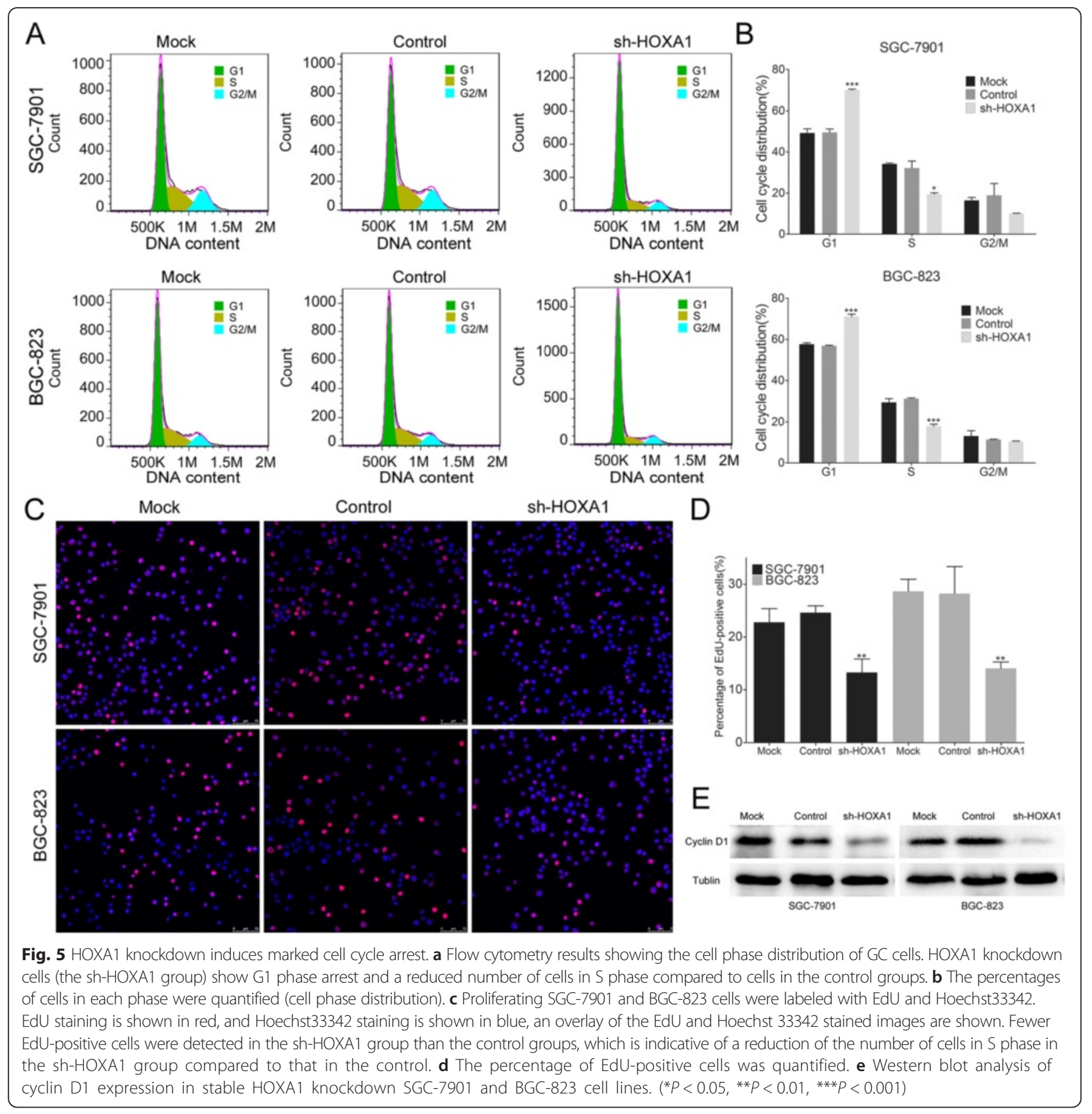

\section{Correlation of HOXA1 and cyclin D1 expression with clinicopathological parameters}

The expression of HOXA1 and cyclin D1 was assessed by IHC analysis using a TMA of 264 primary GC cases paired with normal mucosae and 104 metastatic lymph nodes.

We detected significant differences in HOXA1 expression among normal mucosae, GC tissues, and LNM (Table $1, P<0.001$ ). HOXA1 staining was mainly observed in the nuclei of GC cells, and was detected in the cytoplasm (Fig. 6). As shown in Table 1, HOXA1 was obviously upregulated in $54.5 \%(144 / 264)$ of the primary cancer specimens, whereas HOXA1 was upregulated in only $23.1 \%(61 / 264)$ of adjacent normal mucosae. HOXA1 expression in LNM (71.2 \%) was much higher than that in GC tissues (54.5\%), and this difference was significant $(P=0.004)$. The associations between HOXA1 expression and various clinicopathological parameters are shown in Table 2. Elevated HOXA1 expression was significantly associated with the International Union against Cancer (UICC) stage $(P<0.001)$, invasion depth $(P=0.040)$, nodal involvement $(P=0.004)$, and differentiation $(P<0.001$; Table 2$)$. 
Table 1 Expression of HOXA1 and cyclin D1 in normal mucosae, GC tissues, and lymph node metastases

\begin{tabular}{|c|c|c|c|c|}
\hline \multirow{2}{*}{$\begin{array}{l}\text { Expression of HOXA1 } \\
\text { or cyclin D1 }\end{array}$} & \multicolumn{3}{|l|}{ Tissue samples } & \multirow[t]{2}{*}{$P$ value } \\
\hline & $\begin{array}{l}\text { Normal mucosae } \\
(\mathrm{n}=264)(\%)\end{array}$ & $\begin{array}{l}\text { GC tissues } \\
(n=264)(\%)\end{array}$ & $\begin{array}{l}\text { LNM } \\
(n=104)(\%)\end{array}$ & \\
\hline \multicolumn{5}{|l|}{ HOXA1 } \\
\hline Negative & 203 (76.9) & $120(45.5)$ & $30(28.8)$ & $<0.001^{*, * *}$ \\
\hline Positive & $61(23.1)$ & $144(54.5)$ & $74(71.2)$ & $0.004^{* * * * *}$ \\
\hline \multicolumn{5}{|l|}{ cyclin D1 } \\
\hline Negative & 231 (87.5) & $127(48.1)$ & $41(39.4)$ & $<0.001^{* * * * * *}$ \\
\hline Positive & $33(12.5)$ & 137 (51.9) & $63(60.6)$ & 0.132 \\
\hline \multicolumn{5}{|l|}{ HOXA1/cyclin D1 } \\
\hline Both negative & $170(64.4)$ & 89 (33.7) & $24(23.1)$ & $<0.001^{* * * * * * * *}$ \\
\hline One positive & $94(35.6)$ & $69(26.1)$ & $23(22.1)$ & $0.033^{* * * * * * * * *}$ \\
\hline Both positive & $0(0.00)$ & $106(40.2)$ & $57(54.8)$ & \\
\hline
\end{tabular}

\section{GC gastric cancer}

LNM lymph node metastases

$P$ value calculated using chi-square test or Fisher's exact test

* Significant difference

Significant difference in the expression of $\mathrm{HOXA1}^{* *}$, cyclin D1 ${ }^{* * * *}$, or HOXA1/cyclin D1 ${ }^{* * * * *}$ among normal mucosae, GC tissues, and LNM

Significant difference in the expression of HOXA $1^{* * *}$ and HOXA1/cyclin $D 1^{* * * * * *}$ between GC tissues and LNM

In addition, significant differences were detected for the cyclin D1 expression in normal mucosae, GC tissues, and LNM (Table $1, P<0.001$ ). Of the 264 primary cancer specimens, $51.9 \%(137 / 264)$ showed positive cyclin D1 expression, whereas only $12.5 \%$ (33/264) of the adjacent normal mucosae were positive (Table 1). However, no significant difference in cyclin D1 expression was found between GC tissues and LNM (Table 1, $P=0.132$ ). Overexpression of cyclin D1 was significantly associated with differentiation (Table 2, $P=0.044$ ).

In addition, of the 144 specimens with positive HOXA1 expression, $73.6 \%(106 / 144)$ showed positive

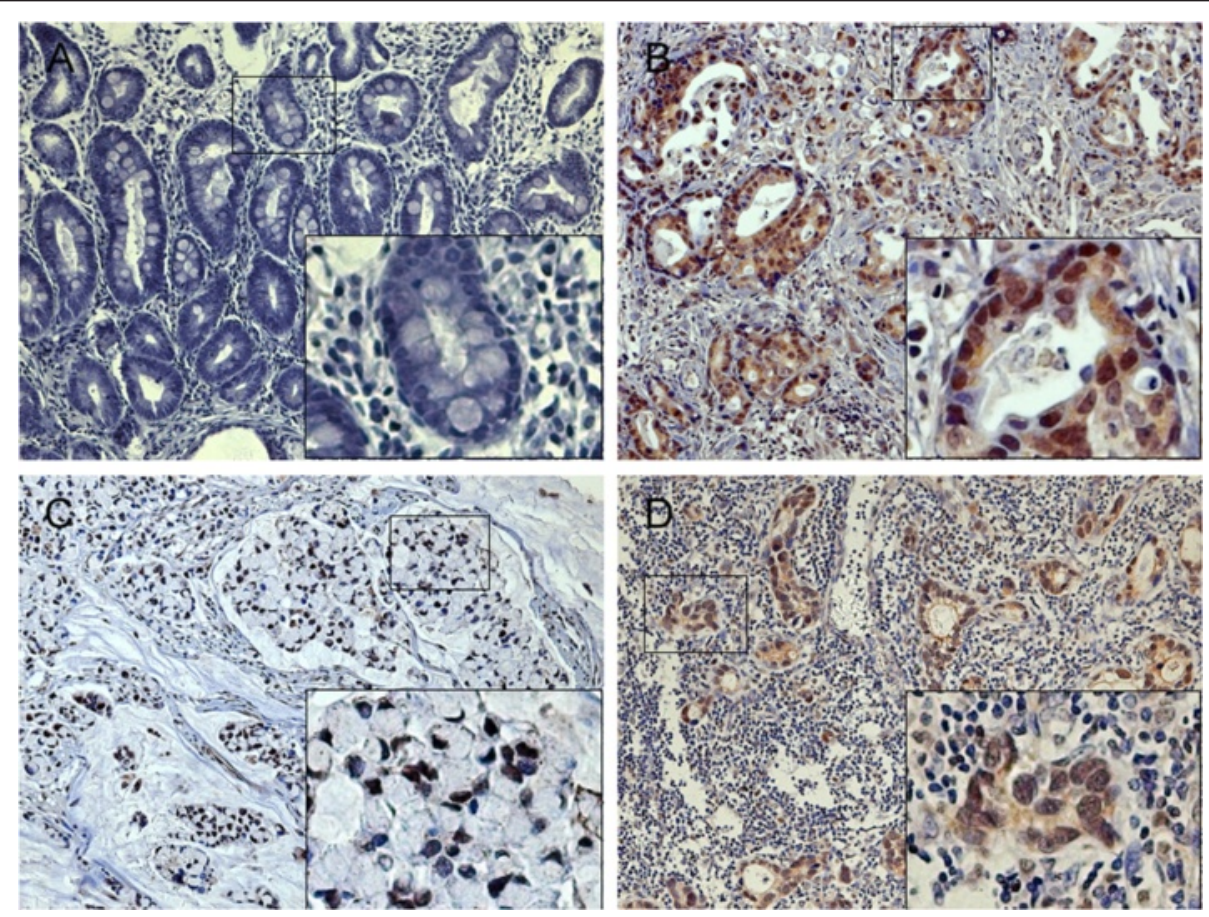

Fig. 6 Immunohistochemical staining of HOXA1 expression in normal and gastric cancer tissues. HOXA1 staining was observed mainly in the nuclei of GC cells and in the cytoplasm. HOXA1 expression was much higher in the GC tissues than in the adjacent normal mucosae. Normal gastric tissue showing negative HOXA1 expression (a); Positive HOXA1 staining in moderately differentiated GC tissue (b), signet ring cell carcinoma (c) and metastatic lymph nodes (d). Original magnification, 200× (400× for inset images) 
Table 2 Relationship between clinicopathologic parameters and HOXA1 or cyclin D1 protein expression in gastric cancer $(n=264)$

\begin{tabular}{|c|c|c|c|c|c|c|c|}
\hline \multirow[t]{2}{*}{ Characteristics } & \multirow[t]{2}{*}{ Total } & \multicolumn{2}{|c|}{ HOXA1 expression } & \multirow[t]{2}{*}{$P$ value } & \multicolumn{2}{|c|}{ Cyclin D1 expression } & \multirow[t]{2}{*}{$P$ value } \\
\hline & & Negative (120) & Positive (144) & & Negative (127) & Positive (137) & \\
\hline Age(years) & & & & 0.457 & & & 0.845 \\
\hline$<65$ & 121 & 58 & 63 & & 59 & 62 & \\
\hline$\geq 65$ & 143 & 62 & 81 & & 68 & 75 & \\
\hline Gender & & & & 0.095 & & & 0.712 \\
\hline Male & 157 & 78 & 79 & & 77 & 80 & \\
\hline Female & 107 & 42 & 65 & & 50 & 57 & \\
\hline T stage & & & & $0.040^{*}$ & & & 0.816 \\
\hline $\mathrm{T} 1$ & 76 & 44 & 32 & & 38 & 38 & \\
\hline $\mathrm{T} 2$ & 42 & 20 & 22 & & 22 & 20 & \\
\hline T3 & 118 & 47 & 71 & & 53 & 65 & \\
\hline $\mathrm{T} 4$ & 28 & 9 & 19 & & 14 & 14 & \\
\hline N stage & & & & $0.004^{*}$ & & & 0.179 \\
\hline NO & 116 & 67 & 49 & & 56 & 60 & \\
\hline N1 & 91 & 35 & 56 & & 48 & 43 & \\
\hline N2 & 40 & 13 & 27 & & 19 & 21 & \\
\hline N3 & 17 & 5 & 12 & & 4 & 13 & \\
\hline M stage & & & & 0.355 & & & 0.751 \\
\hline MO & 254 & 117 & 137 & & 123 & 131 & \\
\hline M1 & 10 & 3 & 7 & & 4 & 6 & \\
\hline UICC stage & & & & $<0.001^{*}$ & & & 0.400 \\
\hline 1 & 95 & 54 & 41 & & 49 & 46 & \\
\hline$\|$ & 48 & 28 & 20 & & 24 & 24 & \\
\hline III & 89 & 28 & 61 & & 43 & 46 & \\
\hline IV & 32 & 10 & 22 & & 11 & 21 & \\
\hline Differentiation & & & & $<0.001^{*}$ & & & $0.044^{*}$ \\
\hline High & 47 & 33 & 14 & & 30 & 17 & \\
\hline Moderate & 42 & 20 & 22 & & 21 & 21 & \\
\hline Low & 175 & 67 & 108 & & 76 & 99 & \\
\hline
\end{tabular}

*Significant association among variables $(P<0.05)$

cyclin D1 expression. We found a statistically significant correlation between HOXA1 and cyclin D1 expression ( $\mathrm{r}=0.476, P<0.001$, Table 3$)$, and HOXA1 and cyclin D1 expression were detected in the same location of one tumor specimen (Fig. 7). These results demonstrated that there was a correlation between HOXA1 and cyclin D1 in GC.

Table 3 Association between HOXA1 and cyclin D1 expression in gastric cancer tissues

\begin{tabular}{lccccc}
\hline Sample & \multicolumn{2}{c}{ Cyclin D1 expression } & $r$ & $P$ value \\
\cline { 2 - 3 } & Negative & Positive & & \\
\hline HOXA1 negative & 89 & 31 & 0.476 & $<0.001$ \\
HOXA1 positive & 38 & 106 & & \\
\hline
\end{tabular}

Survival analysis and prognostic significance of HOXA1 and/or cyclin D1 expression

To assess the possible association between the expression of HOXA1 and/or cyclin D1 in GC tumors and patient survival, Kaplan-Meier curves and the log-rank test were used to determine DFS and OS in 264 patients who underwent radical gastrectomy (Fig. 8). Patients with HOXA1-positive tumors had a poorer DFS $(P<0.001)$ and OS $(P<0.001)$ than patients with HOXA1-negative tumors (Fig. 8a). Cyclin D1 was also significantly associated with DFS $(P<0.001)$ and OS $(P<0.001$; Fig. $8 b)$. To assess concomitant HOXA1 and cyclin D1 protein expression, we divided the specimens into three groups: group 1, tumors exhibiting no HOXA1 or cyclin D1 expression (HOXA1-/cyclin D1-, 89 specimens); group 2, tumors with abnormal expression of one protein (HOXA1-/cyclin 


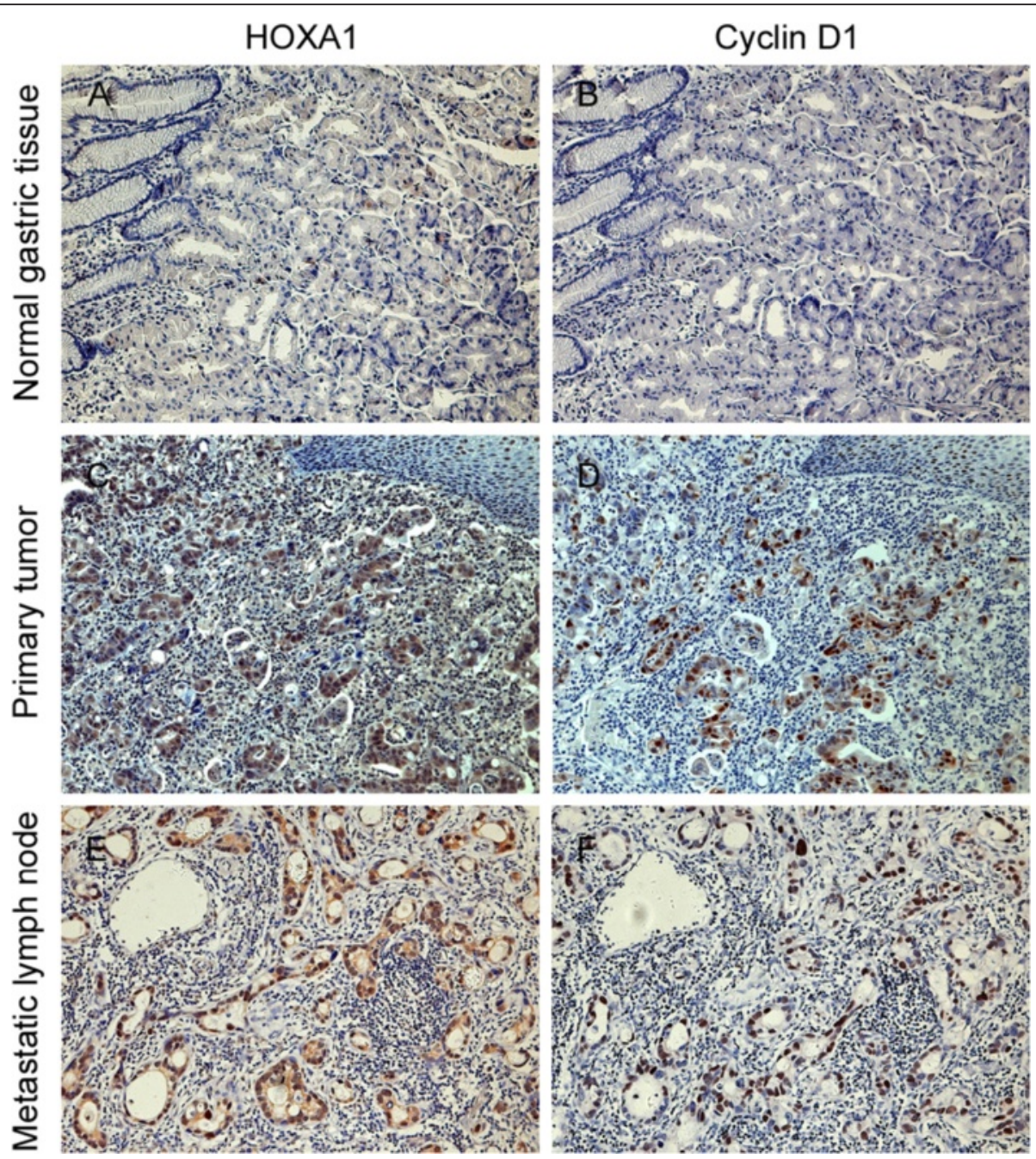

Fig. 7 Expression of HOXA1 and cyclin D1 in normal, tumor, and metastatic lymph node tissues. HOXA1 and cyclin D1 expression were detected in the same location in one tumor specimen. Negative HOXA1 and cyclin D1 staining in normal gastric tissue (a-b). Positive HOXA1 and cyclin D1 staining in GC tissue (c-d), and metastatic lymph nodes (e-f). Original magnification, 200x

D1+ or HOXA1+/cyclin D1-, 69 specimens); and group 3, tumors with abnormal expression of both proteins (HOXA1+/cyclin D1+, 106 specimens). Group 1 showed better DFS and OS than group 2, and group 3 showed the worst DFS and OS $(P<0.001$; Fig. 8c).

In univariate analysis, patients with HOXA1-positive or cyclin D1-positive tumors had a markedly lower OS and DFS than patients with HOXA1-negative or cyclin D1negative tumors (HOXA1, OS, HR 4.601 [95 \% CI 2.504-8.454], $P<0.001$, DFS, HR $4.438 \quad[95 \%$ CI 2.418-8.145], $P<0.001$; cyclin D1, OS, HR 5.893 [95 \% CI 3.159-10.990], $P<0.001$, DFS, HR 5.673 [95 \% CI 3.044-10.572], $P<0.001$ ) (Table 4). Furthermore, lower OS and DFS were also observed in patients with both HOXA1-positive and cyclin D1-positive tumors (OS, HR 9.064 [95 \% CI 4.278-19.203], $P<0.001$; DFS, HR 8.495 [95 \% CI 4.021-17.948], $P<0.001$; Table 4). The multivariate analysis demonstrated that the expression of both HOXA1 and cyclin D1 was an independent prognostic factor for OS (HR 9.905 [95 \% CI 4.45322.031]; $P<0.001$ ) and DFS (HR $8.636 \quad 95 \%$ CI [3.916-19.047]; $P<0.001$ ), but not the expression of HOXA1 or cyclin D1 alone (Table 4).

\section{Discussion}

It is well known that tumor cells and embryonic stem cells share some common pathways related to self-renewal and proliferation and that stem cell genes can play direct roles in tumor progression and/or act as valuable markers of tumorigenesis [31, 32]. HOX genes are typical examples of the close relationship between embryogenesis and tumorigenesis [33]. In general, HOX genes are master regulators of embryonic development and stem cell differentiation; however, their misexpression can lead to changes in 


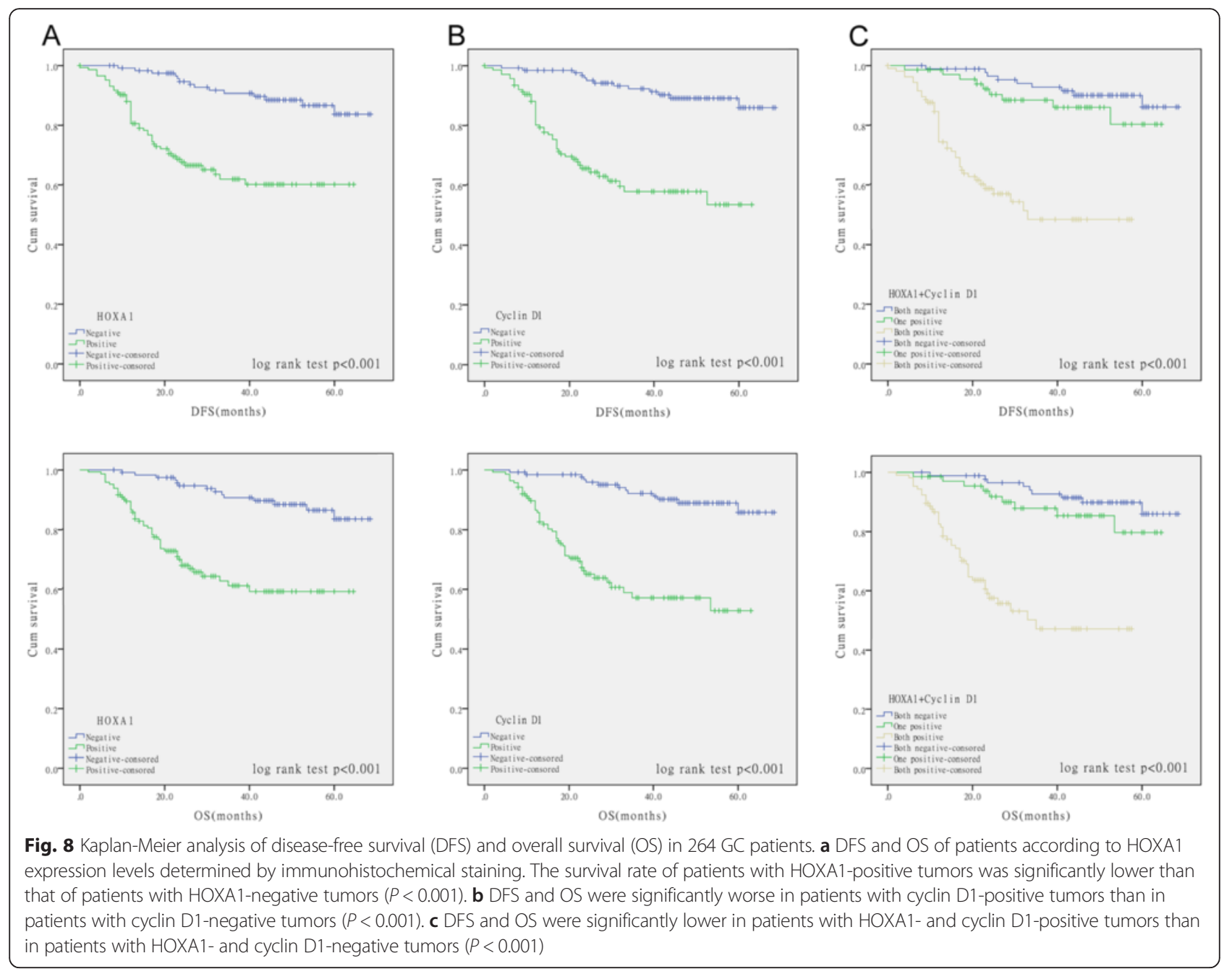

cancer-associated properties, such as proliferation, migration, invasion, and survival [34, 35]. HOXA1, a HOX gene, is a pivotal transcriptional regulator of early embryonic development that plays a critical role in the development of the brainstem, inner ear, and heart in humans and mice $[36,37]$. Overexpression of HOXA1 is associated with a variety of human tumors, including breast, lung, skin, liver, and prostate $[18,19,21,38-40]$. However, the number of studies on HOXA1 expression during GC tumorigenesis and progression are very limited.

In the present study, we showed for the first time that both HOXA1 mRNA and protein expression were upregulated in primary GC tissues compared with the levels in adjacent normal mucosae. To further elucidate the role of HOXA1 in tumor progression, an shRNAbased strategy was used to stably knockdown HOXA1 expression in SGC-7901 and BGC-823 cells, which typically express high levels of HOXA1 protein. Then, we determined, for the first time, that HOXA1 knockdown inhibited GC cell proliferation using CCK- 8 and colony formation assays. Moreover, knockdown of HOXA1 expression also led to a significant reduction in xenograft tumor formation. Recently, Wardwell-Ozgo et al. [18] showed that HOXA1 has a potent effect on cell invasion in melanoma. Meanwhile, Wang et al. [40] reported that HOXA1 knockdown inhibits the growth, invasion, and migration of prostate cancer cells. Coincidentally, our study revealed that HOXA1 knockdown in GC cells suppressed migration and invasion, which indicates the potential involvement of HOXA1 in tumor metastasis. These in vitro and in vivo data suggest that HOXA1 functions in GC cell proliferation, migration, invasion, and tumorigenesis.

Our study showed that knockdown of HOXA1 expression had a marked effect on GC cell proliferation. As the cell cycle is closely related to cell proliferation, we analyzed the effect of HOXA1 knockdown on the cell cycle and found that these cells were arrested in the G1 phase and the number of $S$ phase cells was reduced. Then, we performed an EdU incorporation assay to determine the 
Table 4 Univariate and multivariate analysis for overall survival (OS) and disease-free survival (DFS)

\begin{tabular}{|c|c|c|c|c|c|c|c|c|}
\hline \multirow[b]{3}{*}{ Variable } & \multicolumn{4}{|l|}{ OS } & \multicolumn{4}{|l|}{ DFS } \\
\hline & \multicolumn{2}{|l|}{ Univariate } & \multicolumn{2}{|l|}{ Multivariate } & \multicolumn{2}{|l|}{ Univariate } & \multicolumn{2}{|l|}{ Multivariate } \\
\hline & HR $(95 \%$ Cl) & $P$ value & $\mathrm{HR}(95 \% \mathrm{Cl})$ & $P$ value & $\mathrm{HR}(95 \% \mathrm{Cl})$ & $P$ value & $\mathrm{HR}(95 \% \mathrm{Cl})$ & $P$ value \\
\hline \multicolumn{9}{|l|}{ HOXA1/cyclin D1 } \\
\hline Both negative & 1 & & 1 & & 1 & & 1 & \\
\hline One positive & $1.623(0.643-4.099)$ & 0.305 & $1.800(0.702-4.615)$ & 0.221 & $1.577(0.625-3.983)$ & 0.335 & $1.674(0.652-4.297)$ & 0.284 \\
\hline Both positive & $9.064(4.278-19.203)$ & $<0.001^{*}$ & $9.905(4.453-22.031)$ & $<0.001^{*}$ & $8.495(4.021-17.948)$ & $<0.001^{*}$ & 8.636(3.916-19.047) & $<0.001^{*}$ \\
\hline \multicolumn{9}{|l|}{ HOXA1 } \\
\hline Negative & 1 & & & & 1 & & & \\
\hline Positive & $4.601(2.504-8.454)$ & $<0.001^{*}$ & & & $4.438(2.418-8.145)$ & $<0.001^{*}$ & & \\
\hline \multicolumn{9}{|l|}{ Cyclin D1 } \\
\hline Negative & 1 & & & & 1 & & & \\
\hline Positive & 5.893(3.159-10.990) & $<0.001^{*}$ & & & 5.673(3.044-10.572) & $<0.001^{*}$ & & \\
\hline \multicolumn{9}{|l|}{ Age(years) } \\
\hline$<65$ & 1 & & & & 1 & & 1 & \\
\hline$\geq 65$ & $1.880(1.103-3.202)$ & $0.020^{*}$ & & & $1.862(1.093-3.172)$ & $0.022^{*}$ & $1.738(1.011-2.987)$ & $0.046^{*}$ \\
\hline \multicolumn{9}{|l|}{ Gender } \\
\hline Male & 1 & & & & & & & \\
\hline Female & $1.002(0.603-1.666)$ & 0.992 & & & $1.006(0.605-1.671)$ & 0.982 & & \\
\hline \multicolumn{9}{|l|}{ T stage } \\
\hline $\mathrm{T} 1$ & 1 & & & & 1 & & & \\
\hline $\mathrm{T} 2$ & $2.787(0.786-9.885)$ & 0.113 & & & $2.871(0.809-10.183)$ & 0.103 & & \\
\hline T3 & $7.596(2.709-21.302)$ & $<0.001^{*}$ & & & $7.543(2.690-21.150)$ & $<0.001^{*}$ & & \\
\hline $\mathrm{T} 4$ & $12.061(3.928-37.036)$ & $<0.001^{*}$ & & & $12.200(3.973-37.465)$ & $<0.001^{*}$ & & \\
\hline \multicolumn{9}{|l|}{ N stage } \\
\hline No & 1 & & & & 1 & & & \\
\hline N1 & 4.023(1.799-8.999) & $0.001^{*}$ & & & $4.048(1.810-9.054)$ & $0.001^{*}$ & & \\
\hline N2 & $9.647(4.238-21.959)$ & $<0.001^{*}$ & & & $9.489(4.170-21.592)$ & $<0.001^{*}$ & & \\
\hline N3 & 16.913(6.668-42.899) & $<0.001^{*}$ & & & $18.152(7.149-46.088)$ & $<0.001^{*}$ & & \\
\hline \multicolumn{9}{|l|}{ M stage } \\
\hline Mo & 1 & & & & 1 & & & \\
\hline M1 & $3.082(1.232-7.709)$ & $0.016^{*}$ & & & $3.405(1.361-8.518)$ & $0.009^{*}$ & & \\
\hline \multicolumn{9}{|l|}{ UICC stage } \\
\hline 1 & 1 & & 1 & & 1 & & 1 & \\
\hline$\|$ & $6.795(1.869-24.701)$ & $0.004^{*}$ & $8.168(2.241-29.773)$ & $0.001^{*}$ & $6.867(1.889-24.962)$ & $0.003^{*}$ & $7.172(1.961-26.222)$ & $0.003^{*}$ \\
\hline III & $13.458(4.100-44.180)$ & $<0.001^{*}$ & $14.327(4.325-47.457)$ & $<0.001^{*}$ & $13.355(4.069-43.834)$ & $<0.001^{*}$ & $12.571(3.791-41.678)$ & $<0.001^{*}$ \\
\hline IV & $32.066(9.433-109.001)$ & $<0.001^{*}$ & $30.392(8.750-105.567)$ & $<0.001^{*}$ & $34.583(10.172-117.570)$ & $<0.001^{*}$ & $33.649(9.676-117.020)$ & $<0.001^{*}$ \\
\hline \multicolumn{9}{|l|}{ Differentiation } \\
\hline High & 1 & & & & 1 & & & \\
\hline Moderate & $5.441(1.155-25.634)$ & $0.032^{*}$ & & & $5.499(1.167-25.909)$ & $0.031^{*}$ & & \\
\hline Low & $8.506(2.070-34.961)$ & $0.003^{*}$ & & & $8.581(2.088-35.268)$ & $0.003^{*}$ & & \\
\hline
\end{tabular}

HR hazard ratio; $\mathrm{Cl}$ confidence interval

${ }^{*} P<0.05$ indicates that the $95 \% \mathrm{Cl}$ of the $\mathrm{HR}$ did not include 1

role of HOXA1 in GC progression. The results of the EdU incorporation assay showed that HOXA1 knockdown suppressed GC cell proliferation. More importantly, as EdU is incorporated into DNA during synthesis, the decreased number of EdU-incorporated SGC-7901-shHOXA1 and BGC-823-shHOXA1 cells suggested that the cell cycle 
was arrested in the G1 phase, which was validated in our previous cell cycle analysis showing that the number of $\mathrm{S}$ phase cells was reduced.

As our data show, downregulation of HOXA1 expression suppressed GC cell proliferation mainly by inhibiting the cell cycle. Recently, HOXA1 was reported to stimulate the transcription of cyclin D1, which increases cell proliferation and survival [21]. Another important experiment indicated that upregulation of HOXA1 activated the transcription of cyclin D1 and promoted the G1-S transition in cancer cells [41]. Cyclin D1 plays an important role in cell cycle progression, mainly by affecting regulation of the G1-S-phase transition [30]. Several studies have identified cyclin D1 as involved early in the development of GC $[23,42,43]$. Then, we assessed the expression of cyclin D1 by western blotting in our established stable GC cells. We found that cyclin D1 expression was dramatically decreased in SGC-7901-shHOXA1 and BGC-823-shHOXA1 cells compared to the levels in the corresponding control cells, which indicates that HOXA1 influences tumor cell proliferation by regulating cyclin D1.

Next, we analyzed the relationship between HOXA1 and cyclin D1 on a histological level. We detected the mRNA and protein expression of cyclin D1 and found that both were higher in primary GC tissues than in normal mucosae. Interestingly, increased HOXA1 and cyclin D1 mRNA levels were detected in 27 (56.3 \%) GC tissue samples, and a statistically significant correlation was detected between them $(r=0.651, P<0.001)$. Then, to evaluate the relationship between HOXA1 expression and clinicopathological parameters, we used IHC on a GC TMA with an expanded number of tissue samples and found that HOXA1 expression was significantly associated with UICC stage, invasion depth, nodal involvement, and differentiation. Furthermore, cyclin D1 was more frequently detected in areas of positive HOXA1 staining in GC tissues, and a significant correlation was found between HOXA1 and cyclin D1 expression $(r=0.476, P<0.001)$. Thus, the intimate relationship between HOXA1 and cyclin D1 was confirmed at the histological level.

Recent research indicated that HOXA1 expression is markedly correlated with the overall survival of patients with hepatocellular carcinoma [39]. However, the prognostic value of HOXA1 in GC has not been evaluated. According to the work by Wardwell-Ozgo et al., patients with a higher HOXA1 signature had a shorter time to distant metastasis events [18], suggesting the prognostic implications of HOXA1. And our results also showed that HOXA1 could serve as a prognostic marker for GC with a HR of 4.60 for OS and 4.44 for DFS. Intriguingly, survival analysis indicated that HOXA1-and cyclin D1positive cases had shorter survival time than HOXA1-or cyclin D1-negative cases. What's more, univariate analysis demonstrated that HOXA1-and cyclin D1-positive patients exhibited a much higher HR for OS (9.06 vs 1.62) and DFS (8.50 vs 1.58 ) than HOXA1-or cyclin D1positive patients, indicating that the combination of HOXA1 and cyclin D1 may better prognosticate clinical outcome for GC. Finally, multivariate Cox model analysis confirmed that HOXA1 combined with cyclin D1 was an independent prognostic factor for DFS and OS in GC. Thus, these results suggested that HOXA1, either alone or in combination with cyclin D1, could be a novel prognostic biomarker for GC patients.

\section{Conclusion}

Our research results showed that HOXA1 plays an important role in GC clinical prognosis. First, our data indicated that HOXA1 and cyclin D1 mRNA and protein expression were higher in GC tissues than in the adjacent normal mucosae, and a significant correlation was found between the expression of HOXA1 and cyclin D1. Second, knockdown of HOXA1 expression in GC cells not only inhibited cell proliferation, migration, and invasion and induced changes in the cell cycle in vitro but also suppressed xenograft tumor formation. Moreover, HOXA1 knockdown in GC cells decreased cyclin D1 expression. Third, our clinical data showed that HOXA1, alone or in combination with cyclin D1, may serve as a novel prognostic biomarker for GC. Future studies will focus on the mechanism underlying the role of HOXA1 in the progression of $\mathrm{GC}$ and the potential for targeting HOXA1 in GC treatment.

\section{Abbreviations}

GC: gastric cancer; TMA: tissue microarrays; DFS: disease-free survival; OS: overall survival; UICC: the International Union against Cancer; FBS: fetal bovine serum; qRT-PCR: quantitative real-time PCR; SDS-PAGE: sodium dodecyl sulfate-polyacrylamide gel electrophoresis; CCK-8 assay: Cell Counting Kit-8 assay; EdU incorporation assay: 5-Ethynyl-2'- deoxyuridine incorporation assay; IHC: immunohistochemistry; IS: immunostaining score.

\section{Competing interests}

The authors declare that they have no competing interests.

\section{Authors' contributions}

CZZ and CWY conceived and coordinated the study, drafted and revised the manuscript. CWY, XWZ and YH performed cell culture and related experiments. XWZ, CLS and CCL collected tissue samples and performed the immunohistochemistry. SL and $M Z$ evaluated and scored the staining. FDY and ZHP participated in the design of the study and performed the statistical analysis. All authors read and approved the final manuscript.

\section{Acknowledgements}

This study was supported by the National Natural Science Foundation of China (No. 81172330), the Medical guide project of the Shanghai Science and Technology Committee (No. 15411965700), and the Natural Science Foundation of Shanghai (No. 14ZR1429900).

\section{Author details}

${ }^{1}$ Department of General Surgery, Shanghai General Hospital, Shanghai Jiaotong University School of Medicine, Shanghai 200080, P. R. China.

${ }^{2}$ Department of Pathology, Shanghai General Hospital, Shanghai Jiaotong 
University School of Medicine, Shanghai 200080, P. R. China. ${ }^{3}$ Department of General Surgery, Kashgar Prefecture Second People's Hospital, Kashgar, Xinjiang Uyghur Autonomous Region 844000, P. R. China.

Received: 3 November 2015 Accepted: 13 January 2016

Published online: 21 January 2016

\section{References}

1. Torre LA, Bray F, Siegel RL, Ferlay J, Lortet-Tieulent J, Jemal A. Global cancer statistics, 2012. CA Cancer J Clin. 2015;65:87-108.

2. Siegel R, Ma J, Zou Z, Jemal A. Cancer statistics, 2014. CA Cancer J Clin. 2014;64:9-29.

3. Chen W, Zheng $\mathrm{R}$, Zeng $\mathrm{H}$, Zhang S, He J. Annual report on status of cancer in China, 2011. Chin J Cancer Res. 2015;27:2-12.

4. Hartgrink HH, Jansen EPM, van Grieken NCT, van de Velde CJH. Gastric cancer. Lancet. 2009;374:477-90.

5. Wang ZQ, Sun BJ. c-erbB-2 expression and prognosis of gastric cancer: a meta-analysis. Genet Mol Res. 2015;14:1782-7.

6. Ugras N, Ozgun G, Ocakoglu G, Yerci O, Ozturk E. Relationship between HER-2, COX-2, p53 and clinicopathologic features in gastric adenocarcinoma. Do these biomarkers have any prognostic significance? Turk J Gastroenterol. 2015;25:176-81.

7. Bridges CB. Current Maps of the Location of the Mutant Genes of Drosophila Melanogaster. Proc Natl Acad Sci USA. 1921;7:127-32.

8. Shah N, Sukumar S. The Hox genes and their roles in oncogenesis. Nat Rev Cancer. 2010;10:361-71.

9. Garcia-Fernàndez J. The genesis and evolution of homeobox gene clusters. Nat Rev Genet. 2005;6:881-92.

10. Alharbi RA, Pettengell R, Pandha HS, Morgan R. The role of HOX genes in normal hematopoiesis and acute leukemia. Leukemia. 2013;27:1000-8.

11. Calvo R, West J, Franklin W, Erickson P, Bemis L, Li E, et al. Altered HOX and WNT7A expression in human lung cancer. Proc Natl Acad Sci USA. 2000;97:12776-81

12. Hung $Y$-C, Ueda M, Terai $Y$, Kumagai K, Ueki K, Kanda K, et al. Homeobox gene expression and mutation in cervical carcinoma cells. Cancer Sci. 2003;94:437-41.

13. Hennessy BT, Mills GB. Ovarian cancer: Homeobox genes, autocrine/ paracrine growth, and kinase signaling. The International Journal of Biochemistry \& Cell Biology. 2006;38:1450-6.

14. Shen $\mathrm{H}-\mathrm{CJ}$, Rosen JE, Yang LM, Savage SA, Burns AL, Mateo CM, et al. Parathyroid tumor development involves deregulation of homeobox genes. Endocrine Related Cancer. 2008;15:267-75.

15. Han Y, Tu W-W, Wen Y-G, Li D-P, Qiu G-Q, Tang H-M, et al. Identification and validation that up-expression of HOXA13 is a novel independent prognostic marker of a worse outcome in gastric cancer based on immunohistochemistry. Med Oncol. 2013;30:564-9.

16. Mohankumar KM, Perry JK, Kannan N, Kohno K, Gluckman PD, Emerald BS, et al. Transcriptional Activation of Signal Transducer and Activator of Transcription (STAT) 3 and STAT5B Partially Mediate Homeobox A1Stimulated Oncogenic Transformation of the Immortalized Human Mammary Epithelial Cell. Endocrinology. 2008;149:2219-29.

17. Mohankumar KM, Xu XQ, Zhu T, Kannan N, Miller LD, Liu ET, et al. HOXA1stimulated oncogenicity is mediated by selective upregulation of components of the p44/42 MAP kinase pathway in human mammary carcinoma cells. Oncogene. 2007;26:3998-4008.

18. Wardwell-Ozgo J, Dogruluk T, Gifford A, Zhang Y, Heffernan TP, van Doorn $R$, et al. HOXA1 drives melanoma tumor growth and metastasis and elicits an invasion gene expression signature that prognosticates clinical outcome. Oncogene. 2013;33:1017-26.

19. Brock A, Krause S, Li H, Kowalski M, Goldberg MS, Collins JJ, et al. Silencing HoxA1 by intraductal injection of siRNA lipidoid nanoparticles prevents mammary tumor progression in mice. Science Translational Medicine. 2014;6:217ra2.

20. Trapnell C, Hendrickson DG, Sauvageau M, Goff L, Rinn JL, Pachter L. Differential analysis of gene regulation at transcript resolution with RNA-seq. Nature Biotechnology. 2012;31:46-53.

21. Zhang X, Zhu T, Chen Y, Mertani HC, Lee K-O, Lobie PE. Human growth hormone-regulated HOXA1 is a human mammary epithelial oncogene. J Biol Chem. 2003;278:7580-90.
22. Guo Y, Guo W, Chen Z, Kuang G, Yang Z, Dong Z. Hypermethylation and aberrant expression of Wnt-antagonist family genes in gastric cardia adenocarcinoma. neo. 2011;58:110-7.

23. Arici $D$, Tuncer $E$, Ozer $H$, Simek $G$, Koyuncu $A$. Expression of retinoblastoma and cyclin D1 in gastric carcinoma. neo. 2009;56:63-7.

24. Arnold A. Cyclin D1 in Breast Cancer Pathogenesis. Journal of Clinical Oncology. 2005;23:4215-24.

25. Sauter ER, Yeo U-C, Stemm Von A, Zhu W, Litwin S, Tichansky DS, et al. Cyclin D1 is a candidate oncogene in cutaneous melanoma. Cancer Research. 2002;62:3200-6.

26. Li Z, Wang C, Prendergast G, Pestell RG. Cyclin D1 functions in cell migration. Cell Cycle. 2006;5:2440-2

27. Seo J-H, Jeong E-S, Choi Y-K. Therapeutic effects of lentivirus-mediated shRNA targeting of cyclin D1 in human gastric cancer. BMC Cancer. 2014;14:1-9.

28. Wang W, Sun X-W, Li C-F, LV L, Li Y-F, Chen Y-B, et al. Comparison of the 6th and 7th Editions of the UICC TNM Staging System for Gastric Cancer: Results of a Chinese Single-Institution Study of 1,503 Patients. Ann Surg Oncol. 2010;18:1060-7.

29. Euhus DM, Hudd C, LaRegina MC, Johnson FE. Tumor measurement in the nude mouse. J Surg Oncol. 1986;31:229-34.

30. Pestell RG. New roles of cyclin D1. Am J Pathol. 2013;183:3-9.

31. Reya T, Clevers H. Wnt signalling in stem cells and cancer. Nature. 2005;434:843-50.

32. Ezeh UI, Turek PJ, Reijo RA, Clark AT. Human embryonic stem cell genesOCT4, NANOG, STELLAR, andGDF3 are expressed in both seminoma and breast carcinoma. Cancer. 2005:104:2255-65.

33. Gu Z-D, Shen L-Y, Wang H, Chen X-M, Li Y, Ning T, et al. HOXA13 promotes cancer cell growth and predicts poor survival of patients with esophageal squamous cell carcinoma. Cancer Research. 2009;69:4969-73.

34. Barber BA, Rastegar M. Epigenetic control of Hox genes during neurogenesis, development, and disease. Annals of Anatomy. 2010:192:261-74.

35. Samuel S, Naora H. Homeobox gene expression in cancer: insights from developmental regulation and deregulation. Eur J Cancer. 2005:41:2428-37.

36. Barrow JR, Stadler HS, Capecchi MR. Roles of Hoxa1 and Hoxa2 in patterning the early hindbrain of the mouse. Development. 2000:127:933-44.

37. Makki N, Capecchi MR. Hoxa1 lineage tracing indicates a direct role for Hoxa1 in the development of the inner ear, the heart, and the third rhombomere. Developmental Biology. 2010;341:499-509.

38. Abe M, Hamada J-I, Takahashi O, Takahashi Y, Tada M, Miyamoto M, et al. Disordered expression of HOX genes in human non-small cell lung cancer. Oncol Rep. 2006;15:797-802.

39. Zha T-Z, Hu B-S, Yu H-F, Tan Y-F, Zhang Y, Zhang K. Overexpression of HOXA1 correlates with poor prognosis in patients with hepatocellular carcinoma. Tumor Biol. 2012:33:2125-34.

40. Wang H, Liu G, Shen D, Ye H, Huang J, Jiao L, et al. HOXA1 enhances the cell proliferation, invasion and metastasis of prostate cancer cells. Oncol Rep. 2015;34:1203-10.

41. Cho H-S, Toyokawa G, Daigo Y, Hayami S, Masuda K, Ikawa N, et al. The JmjC domain-containing histone demethylase KDM3A is a positive regulator of the G1/S transition in cancer cells via transcriptional regulation of the HOXA1 gene. Int J Cancer. 2011;131:E179-89.

42. Lee K-H, Lee HE, Cho SJ, Cho YJ, Lee HS, Kim JH, et al. Immunohistochemical analysis of cell cycle-related molecules in gastric carcinoma: prognostic significance, correlation with clinicopathological parameters, proliferation and apoptosis. Pathobiology. 2008:75:364-72.

43. Gao P, Zhou G-Y, Liu Y, Li J-S, Zhen J-H, Yuan Y-P. Alteration of cyclin D1 in gastric carcinoma and its clinicopathologic significance. WJG. 2004:10:2936-9. 